\title{
Semi-automated characterisation of seabed pockmarks in the central North Sea
}

\author{
J. Gafeira, D. Long and D. Diaz-Doce \\ British Geological Survey, West Mains Road, Edinburgh EH9 3LA, UK
}

\begin{abstract}
Pockmarks are indicators of focused fluid seepage, most notably gas such as methane, and can occur in vast numbers in many marine and even in lacustrine environments. The presence and distribution of pockmarks need to be considered in the development of any infrastructure at the seabed. However, manual mapping of these features can be extremely timeconsuming and it is implicitly subjective. An extensive area in the central North Sea, where the seabed comprises a thick sequence of muds and sandy muds of the late glacial Witch Ground Formation, shows numerous inactive pockmarks, typically 20-100 m diameter and 3-4 m deep. Within this area a few larger, active pockmarks, $500 \mathrm{~m}$ diameter and up to 17 $\mathrm{m}$ deep are known. Modern site investigations in this area regularly include multibeam sonar mapping, a technique that collects large volumes of bathymetric data that can be used to produce digital depth models of the seafloor with sufficient resolution to characterize individual pockmarks. This paper presents a semi-automated method to recognize, spatially delineate and characterise morphometrically pockmarks at the seabed. The method comprises two scripts, Pockmark Mapping and Pockmark Characterization, that allow the systematic application of a sequence of well defined tools available within the ESRI ArcGIS toolbox. Almost 4150 pockmarks were mapped applying this method to 18 selected site surveys across the central North Sea. The mapping and morphometric characterization of such vast number of pockmarks allows the identification of certain trends reflecting the hydrodynamic regime, whereas the pockmarks density and spatial distribution appears to be attributable to differences in shallow gas availability and deeper geology controlling fluid migration pathways.
\end{abstract}

\section{INTRODUCTION}

Pockmarks were first reported by King and Maclean (1970) offshore Nova Scotia, Canada. They suggested that gas and/or water from the underlying bedrock was released in sufficient quantities to put fine grained material into suspension where it can drift away from venting point thereby forming a void or pockmark in the seabed sediments. Since then pockmarks have been found within lakes and estuaries, on open shelves and in deep oceans. Within the UK, pockmarks were first discovered in 1970 by a rig site survey in the Forties Field in the North Sea. This area, the Witch Ground Basin, is the primary location of pockmarks on the UK continental shelf (Hovland and Judd, 1988). As well as being identified on the surface, buried pockmarks close to seabed have also been noted in the Witch Ground area. It is thought that the buried pockmarks formed during a short period of increased pockmark eruption frequency around 13,000 years ago, coinciding with a rapid rise in marine temperatures (Long, 1992). Pockmarks within the UK are typically $100 \mathrm{~m}$ diameter and a few metres deep and are usually restricted to muddy sediments. Only a few are larger with diameters greater than $250 \mathrm{~m}$ and depths greater than 10 $\mathrm{m}$. These larger pockmarks show signs of active gas seepage such as bubbles in the water column above and acoustic blanking below in seismic profiles. They often also show evidence of carbonate cementation of the seafloor (Hovland and Judd, 1988) which can create a distinct seabed habitat and some have been nominated for protection under the European Habitats Directive (JNCC, 2011). These carbonates, methane derived authigenic carbonate (MDAC), are formed when methane is oxidized anaerobically by a microbial consortium of archaea and sulphate reducing bacteria (Boetius et al., 2000). Grains of the normal seafloor sediments are bound by carbonate cement (typically $\mathrm{CaCO}_{3}$ ) where the carbon is derived from the methane.

\section{POCKMARK MAPPING}

Profiling data such as echosounder or high resolution seismic (chirp, boomer and sparker) will display pockmarks on the seabed as v-shaped notches. The later may also depict buried pockmarks. This data indicates their presence but does not give information on their size as profiles through the centre of a pockmark will differ significantly from a profile that only clips the edge of the depression. Therefore these data cannot be used for the morphological characterisation of pockmark for comparative purposes. Additionally, due to the spacing of profile data, estimates of pockmark density have a large degree of uncertainty. Data sets such as sidescan sonar or multibeam echosounder that display the seafloor allow an indication of pockmark size and density, allowing comparisons in pockmark geometry to be made. However manual mapping of these features can be extremely time-consuming and it is implicitly subjective and any analysis of such data is vulnerable to error by the interpreter. In addition sidescan sonar mapping and the recognition of pockmarks can be dependent on the incident 
angle. There have been attempts to automatically map sidescan features by examining the colour on analogue records (Linnet et al., 1991). However, as such data sets have been acquired digitally over the last decade, they offer an opportunity for the development better automated mapping methods that provide a greater consistency and minimise interpretation errors (Andrews et al., 2010).

\section{Regional geological setting}

The central North Sea has been the location of UK pockmarks studies since the 1970s (McQuillin and Fannin, 1979). The Fladen Ground or Witch Ground Basin is an extensive area of muds reaching water depths greater than $150 \mathrm{~m}$. It was a depocentre for fine grained sedimentation during deglaciation when locally in excess of $30 \mathrm{~m}$ of Witch Ground Formation sediments were deposited very rapidly creating a thick sequence of very soft muds. Acoustic blanking is evident in the shallow section below the Witch Ground Formation, suggesting shallow gas is trapped at selected horizons within the Quaternary sequence (Andrews et al., 1990); such accumulations support the hypothesis that the pockmarks were form by gas escape. The basin shallows to about $120 \mathrm{~m}$ water depth where the seabed sediments are sandy muds and locally muddy sands. The area has been well studied as it is the location of many of the earliest hydrocarbon discoveries on the UKCS including Forties, Tartan and Britannia (Judd, 2001).

\section{Data}

\section{Multibeam data sets}

The British Geological Survey (BGS) has gathered various multibeam data sets over the last decade from the central North Sea (Fig. 1). These include data collected for the Department of Trade and Industry's (now DECC) Strategic Environment Assessment programme (SEA programme; www.offshore-sea.org.uk). The second part of this programme (SEA2) included the central North Sea and in 2001 a series of blocks of multibeam were collected by OSAE (now Fugro), onboard the R/V Kommander Jack, over target areas selected as possible sites of large and active pockmarks reported in various site surveys. The SEA2 survey used a Simrad EM1002 and the data was processed to produce a xyz volume with $2 \mathrm{~m}$ spacing (Judd, 2001).

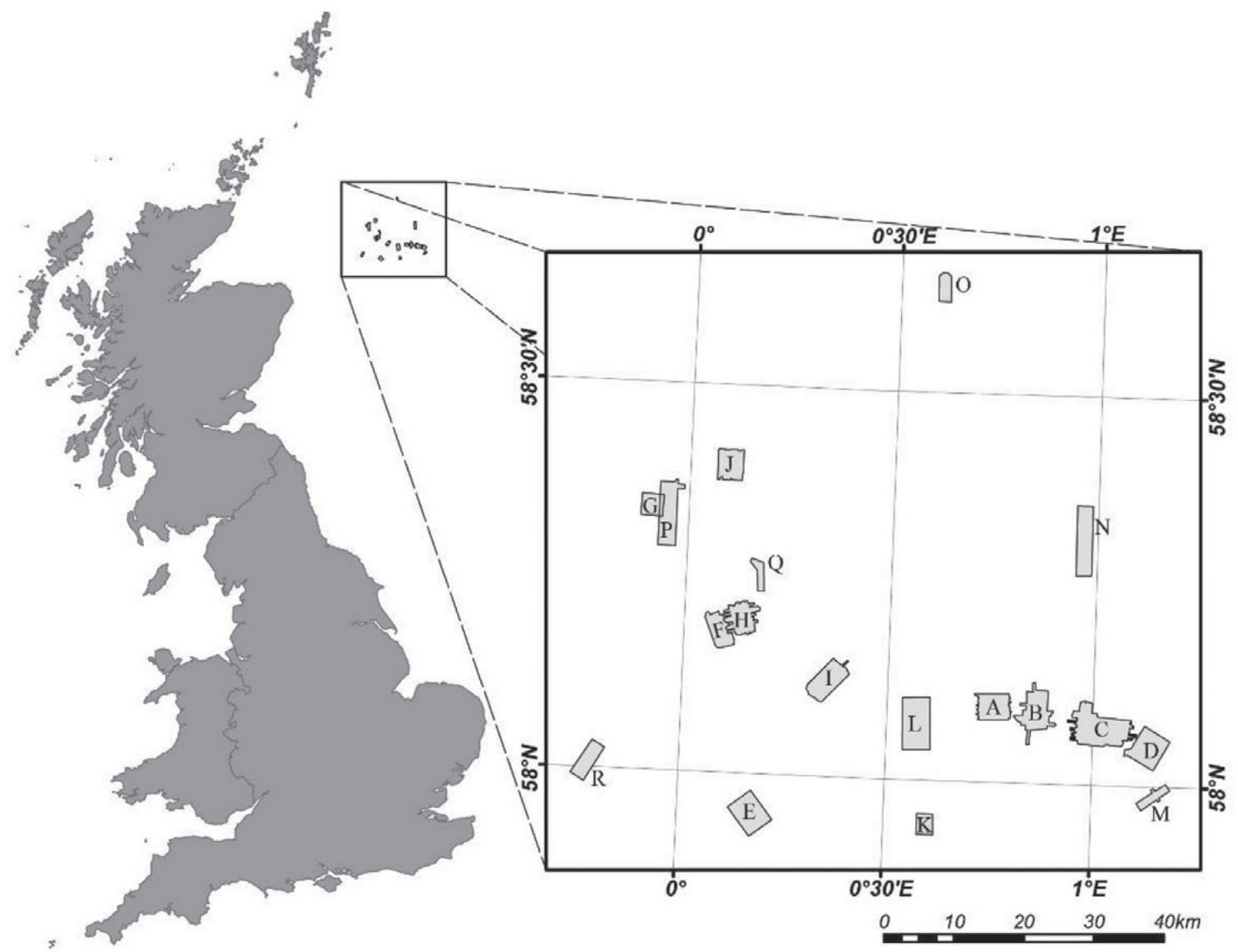


During the last 10 years, many operators have commissioned multibeam surveys as part of site surveys for exploration wells. BGS has sought copies of these data to place in a national archive of offshore data. This information is used by BGS to supplement its own data to update maps of the seafloor. Table 1 shows a description of data sets used in this study, whose resolution range from 1 to 10 metres. All the xyz data sets were transformed into ESRI ArcGIS grids that were the basis for the pockmarks identification and subsequent analyses.

TABLE 1 Description of the multibeam data sets used in this study. Surveys location is shown on Fig. 1.

\begin{tabular}{|c|c|c|c|c|c|c|c|}
\hline \multicolumn{2}{|r|}{ Data set } & Company & Licence block & Date & Gathered by & Area $\mathbf{k m}^{2}$ & xyz data \\
\hline A & Britannia A & ConocoPhillips & $15 / 29$ & 2005 & Fugro & 16.92 & $2 \mathrm{~m}$ grid \\
\hline B & Britannia B & ConocoPhillips & $15 / 30$ & 2003 & Fugro & 21.76 & $5 \mathrm{~m}$ grid \\
\hline $\mathrm{C}$ & Britannia C & ConocoPhillips & $15 / 30 \& 16 / 26$ & 2005 & Fugro & 36.10 & $2 \mathrm{~m}$ grid \\
\hline D & Britannia D & ConocoPhillips & $16 / 26$ & 2003 & Fugro & 21.31 & $5 \mathrm{~m}$ grid \\
\hline $\mathrm{E}$ & Buchan & Talisman Energy & $21 / 1$ & 2003 & Fugro & 21.15 & $2 \mathrm{~m}$ grid \\
\hline $\mathrm{F}$ & Ivanhoe & Amerada Hess & $15 / 21$ & 2003 & Fugro & 14.06 & $2 \mathrm{~m}$ grid \\
\hline G & Petronella & Talisman Energy & $14 / 20$ & 2006 & UTEC & 9.64 & $1 \mathrm{~m}$ grid \\
\hline $\mathrm{H}$ & Rob Roy & Amerada Hess & $15 / 21$ & 2001 & Fugro & 17.26 & $10 \mathrm{~m}$ grid \\
\hline I & Roisin & Talisman Energy & $15 / 27$ & 2003 & Fugro & 19.50 & $2 \mathrm{~m}$ grid \\
\hline $\mathrm{J}$ & Tartan Terrace & Talisman Energy & $15 / 16$ & 2003 & Fugro & 15.59 & $2 \mathrm{~m}$ grid \\
\hline $\mathrm{K}$ & SEA2 Box 1 & DTI & $21 / 3 \& 21 / 4$ & 2001 & OSAE & 6.96 & $2 \mathrm{~m}$ grid \\
\hline $\mathrm{L}$ & SEA2 Box 2 & DTI & $15 / 28$ & 2001 & OSAE & 29.78 & $2 \mathrm{~m}$ grid \\
\hline M & SEA2 Box 3 & DTI & $22 / 1$ & 2001 & OSAE & 6.27 & $2 \mathrm{~m}$ grid \\
\hline $\mathrm{N}$ & SEA2 Box 4 & DTI & $15 / 25$ & 2001 & OSAE & 22.68 & $2 \mathrm{~m}$ grid \\
\hline $\mathrm{O}$ & SEA2 Box 6 & DTI & $15 / 13 \& 15 / 14$ & 2001 & OSAE & 6.88 & $2 \mathrm{~m}$ grid \\
\hline $\mathrm{P}$ & SEA2 Box 7 & DTI & $15 / 16 \& 15 / 17$ & 2001 & OSAE & 23.88 & $2 \mathrm{~m}$ grid \\
\hline Q & SEA2 Box 8 & DTI & $15 / 21$ & 2001 & OSAE & 4.92 & $2 \mathrm{~m}$ grid \\
\hline $\mathrm{R}$ & SEA2 Box 9 & DTI & $14 / 29,14 / 30 \& 20 / 4$ & 2001 & OSAE & 11.74 & $2 \mathrm{~m}$ grid \\
\hline
\end{tabular}

\section{Method}

The method presented here is a multi-stage process using a sequence of well defined tools available within the ESRI ArcGIS Toolbox. This sequence of tools was compiled into two scripts that allow easy and systematic application. The first script, Pockmark Mapping Script, includes the identification and delineation of pockmarks and creates polygons which represent the areas of the seabed shaped by pockmarks. The second script, Pockmark Characterization Script, extracts the morphometric characteristics for each individual pockmark and populates the attribute table of the polygons created by the Pockmark Mapping Script, with morphometric attributes, such as Mean Slope. The input data set required is merely a digital depth model (DDM) that is used to generate three output shapefiles: 1) a polygon shapefile that delineates the pockmarks at seabed, 2) a point shapefile that shows the centroid of the referred polygons, and 3) a point shapefile that marks the deepest point within each pockmark mapped. This last shapefile is likely to correspond to the main source point, or vent, of the fluid escape that originated the pockmark. These output shapefiles include all the morphometric attributes measured for each mapped pockmark within their table of attributes. The first script requires the definition, by the user, of four threshold 
values for the pockmarks: Minimum Depth, Minimum Area, Minimum Area/Perimeter Ratio and Buffer Distance. These threshold values can be estimated by trial and error and can be changed for each DDM. Visual assessment of the areas delineated by the first script should allow the user to verify if the threshold values were correctly chosen. The choice of the most appropriate threshold values for each DDM will decide the accuracy of the final output. However, accuracy of the output will always depend on the quality of the input data i.e., the resolution of the original DDM.

\section{Pockmark Mapping Script}

Pockmarks Identification

We consider a pockmark as a confined depression in a DDM, therefore it is possible to employ hydrological algorithms developed to identify sinks on digital elevation models. Sinks, in this context, are cells with an undefined drainage direction since no cells surrounding it are lower. The "Fill" tool, based on such hydrological algorithms, defines what would be the lowest elevation on the rim of a sink depression (i.e., the overflow point if the depression was being filled) and replaces the depth value of all the cells lower than the overflow point by its value (Fig. 2).

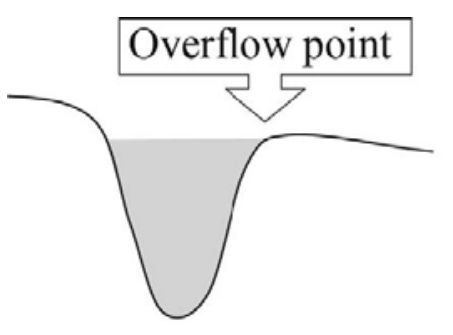

Figure 2 Diagram showing the location of the overflow point.

Figure 3 shows the sequence of steps within the Pockmark Mapping Script. The first step of this script (step 1.1) is the application of the "Fill" tool to the given bathymetric data set. The new surface created is then subtracted from the original DDM using the "Minus" tool (step 1.2). That surface will only present values different from zero for the confined depressions.

\section{Pockmark delineation}

The raster resulting from step 1.2 is in step 1.3 (Fig. 3) reclassified into two classes (" 0 " and " 1 "), where all values higher than the Minimum Depth threshold (0.5 metres for these study areas) will belong to class " 1 " and all values lower Minimum Depth threshold will belong to class " 0 ". These value changes are saved to a new output raster that is transformed, using the "Raster to Polygon" tool, into a polygon shapefile.

\section{Polygon selection}

Small irregularities on the seabed or artefacts on the data can create areas that may be mistakenly delineated as pockmarks. Establishing both Minimum Area and Minimum Area/Perimeter Ratio minimises that, since very small polygons or polygons with a small ratio are more likely to be spurious pockmarks or artefacts whilst polygons with a large ratio are more likely to be real pockmarks. Polygons with an area/perimeter ratio lower than the set value for the Area/Perimeter Ratio and/or with an area smaller than Minimum Area threshold are automatically deleted in step 1.4 (Fig. 3). We applied a threshold of 100 square metres for Minimum Area and 4.5 metres for Area/ Perimeter Ratio.

\section{Define polygons outline}

The polygons' outlines are progressively changed in steps 1.5 and 1.6 (Fig. 3), so that the geometry of the delineated features will approximate to the characteristic shape of the pockmarks at seabed. In step 1.5, a buffer is applied to the polygons created at step 1.3 to compensate for the fact that the delineation process was based on the internal contour line corresponding to the Minimum Depth threshold. The Buffer Distance should reflect approximately the distance, in plan-view, from the internal contour line delineated to the actual rim of the pockmark. A Buffer Distance of 7.5 metres was applied based on the average

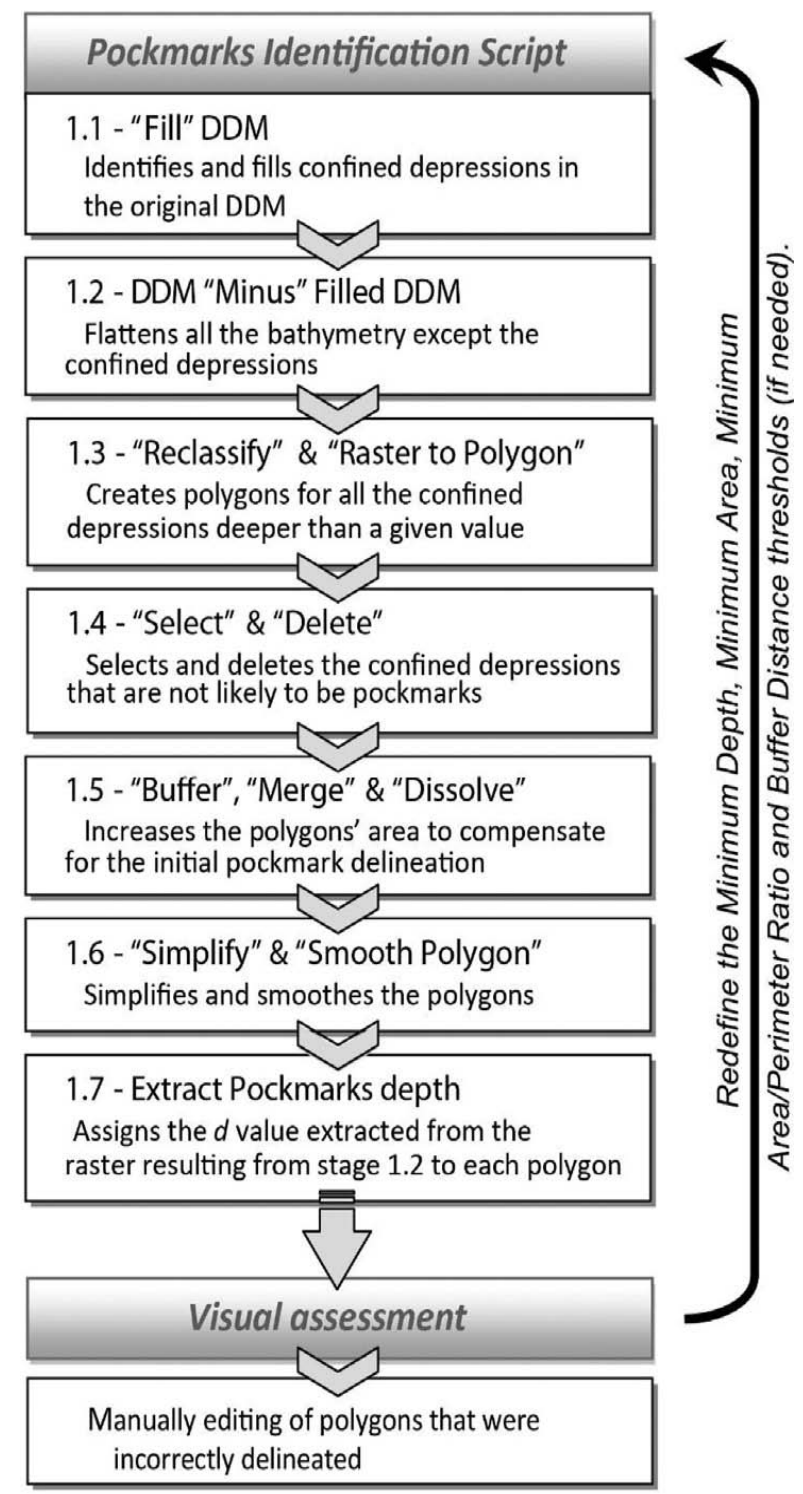

FIGURE 3 Diagram of the multi-steps compiled within the Pockmark Mapping Script. 
slope and size of the pockmarks within the various study areas. The buffer polygons are then "merged" and "dissolved" to create a new polygon shapefile that will be "simplified" and "smoothed" at step 1.6. This last step is especially important for the cases when the data was acquired during rough weather, and which may lead to artefacts in the data set that will generate polygons with irregular outline.

\section{Extract Pockmark Depth}

The depth value of each pockmark is extracted in step 1.7 from the raster resulting from step 1.2 by using the "Extract by mask", "Raster to point" and "Spatial Join" tools. These values are added to the attribute table of the shapefile created at 1.6 (Fig. 3). This will be the final result of the first script, a shapefile delineating the pockmarks at seabed with an attribute table that compiles a) Area (in square metres), b) Perimeter (in metres), c) Area/ Perimeter Ratio and d) Pockmark Depth (in metres).

\section{Visual assessment and manual editing}

Once the shapefile delineating the pockmarks was obtain for each study area, it was visually assessed. Visual assessment of the polygons comprised overlaying the generated shapefile on to either the original bathymetric data or the derived surfaces, such as the slope map. This can help the user to decide if the acquired mapping results are satisfactory and to decide if it is necessary to manually edit sporadic polygons that were inaccurately mapped or to add pockmarks that were missed by the automated methods. With the appropriate threshold values, the number of polygons that require manual editing should never exceed $10 \%$ of total number of pockmarks delineated by the first script. If the percentage of polygons requiring manual editing is higher, then it may be convenient to redefine the threshold values initially chosen and to re-run the Pockmarks Mapping Script (Fig. 3). However, most of the study areas did not require such a level of manual editing nor the redefinition of the threshold values.

Manual editing is usually required mainly for the following two reasons: the location of the pockmark relative to the study area edges and the spatial proximity of several pockmarks. Pockmarks at the periphery of the data set may not be considered as enclosed depressions by the Pockmark Mapping Script, and therefore they may a) not be delineated or b) be delineated but having underestimated areas and depths. Additionally, adjacent pockmarks can be delineated as a single feature, if a marked ridge between the two pockmarks is absent. In these situations, it will be necessary to use the editing tools within ArcGIS to manually add, correct or split delineated polygons. If there are too many multiple pockmarks that are delineated as one, the threshold value for Minimum Depth should be increased.

\section{Pockmark Characterization Script}

Recalculate attribute table

After manually editing the outline of some of the pockmark polygons, the shape of the polygons will have changed but the attribute table will still be the same, therefore the information on it may be partially incorrect. Therefore, the first step of the second script (step 2.1, on Fig. 4) is to recalculate the Area, Perimeter, Area/Perimeter Ratio and Pockmark Depth values for each feature.

\section{Extract Water Depth information}

On step 2.2 (Fig. 4) the deepest value within each pockmark is extracted directly from the original DDM, using "Extract by mask", "Raster to point" and "Spatial Join" tools as described to the extraction of the Pockmark Depth values. This value is referred to here as the Maximum Water Depth (or MaxWD) and is added to the attribute table. The Minimum Water Depth (MinWD) is calculated by subtracting the Pockmark Depth (d) of the pockmark from the MaxWD (Fig. 5). In this way the MinWD values are not affected by the final shape of the pockmark polygons but will always reflect the water depth of the "pouring point" defined by the "Fill" tool. This is useful as it gives consistent water depth for adjacent pockmarks after manual splitting. Note, it is impossible to automatically extract accurate $d$ values, and therefore accurate MinWD values, for the pockmarks at the periphery of the data set as the "pouring point" will be define for the incomplete morphology of the pockmark.

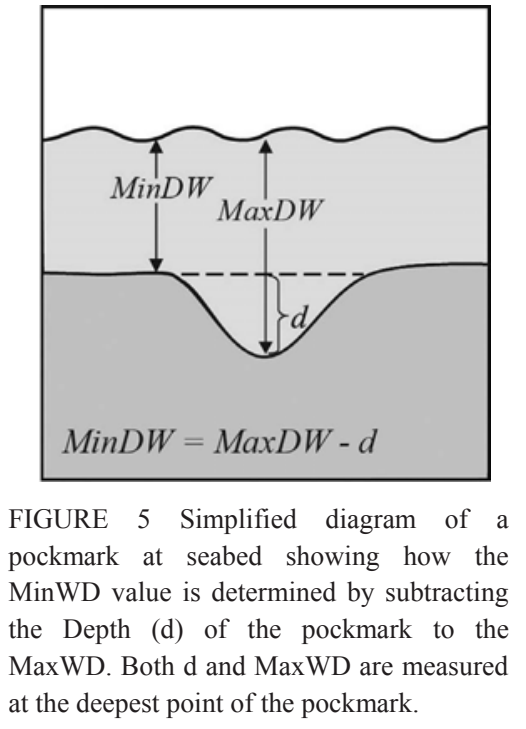




\section{Pockmarks Characterization Script}

\section{1 - Recalculate pockmarks' attributes \\ Area, Perimeter, A/P ratio and $d$}

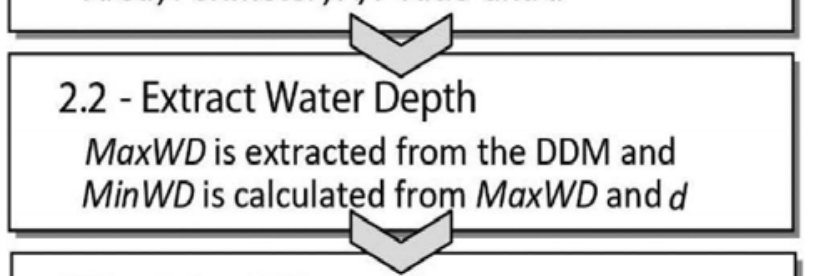

\section{3 - Extract Slope}

Both MaxSlope and MeanSlope are extracted and assigned to each polygon

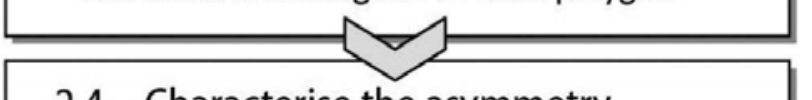

\section{4 - Characterise the asymmetry Both polygons' major-axis and its azimuth are measured using the Polygon Diameter Azimuth Tool and assigned to each polygon}

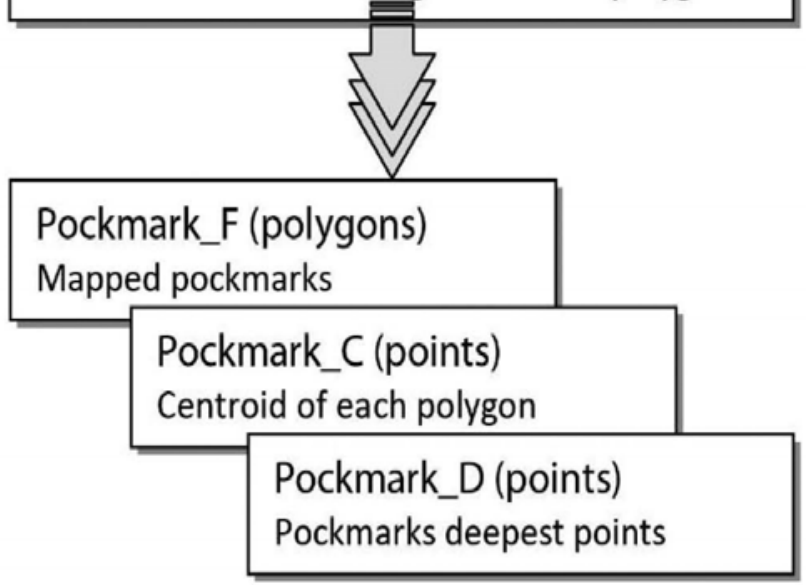

FIGURE 4 Diagram of the multi-steps compiled within the Pockmark Characterization Script and the resulting three shapefiles used to characterise the delineated pockmarks.

clockwise from North and the major-axis length is measured in metres. This information is then added to two new fields (Azimuth and MajorAxisLength) in the attribute table (step 2.4, on Fig. 4).

\section{FINAL OUTCOMES}

At the end of Pockmark Characterization Script the user will have three shapefiles that describe the delineated pockmarks: 1) a polygon shapefile that shows the pockmark, 2) a point shapefile that shows the centre of the pockmark outline, and 3) a point shapefile that shows the position of the deepest cell within the pockmark (Fig. 6). All of the shapefiles are completed with the full attribute table that comprises the following list of attribute fields: Area (m), Perimeter (m), Area/Perimeter Ratio, Depth (m), MaxWD, MinWD, MaxSlope, MeanSlope, Azimuth and MajorAxisLength.
Extract Slope information

On step 2.3 (Fig. 4) the "Extract by mask", "Raster to point" and "Spatial Join" tools are once again applied, this time to extract both maximum slope (MaxSlope) and mean slope (MeanSlope) for each pockmark.

\section{Shape characterisation}

Hovland et al. (2002) identified six morphological classes of pockmarks: 1) unit pockmarks, 2) 'normal' (regular and asymmetric) pockmarks, 3) elongated pockmarks, 4) 'eyed' pockmarks, 5) 'strings' pockmarks, and 6) 'complex' pockmarks. According to these authors 'normal' pockmarks are circular depressions and often this class is assumed in pockmark studies. However, within this study area most pockmarks are not circular but fit within the 'Elongated' pockmark class (Hovland et al., 2002). They are depressions where one axis is much longer than the other and are often asymmetric in profile. These divergences from circular are attributes that can be determined for each pockmark from the multibeam data sets and used to characterise the pockmark morphology. To assess their eccentricity we use an ArcScript called Polygon Diameter Azimuth Tool, developed by Brundage (2006), that finds the polygons' major-axis and measures its azimuth and length. The azimuth is measured

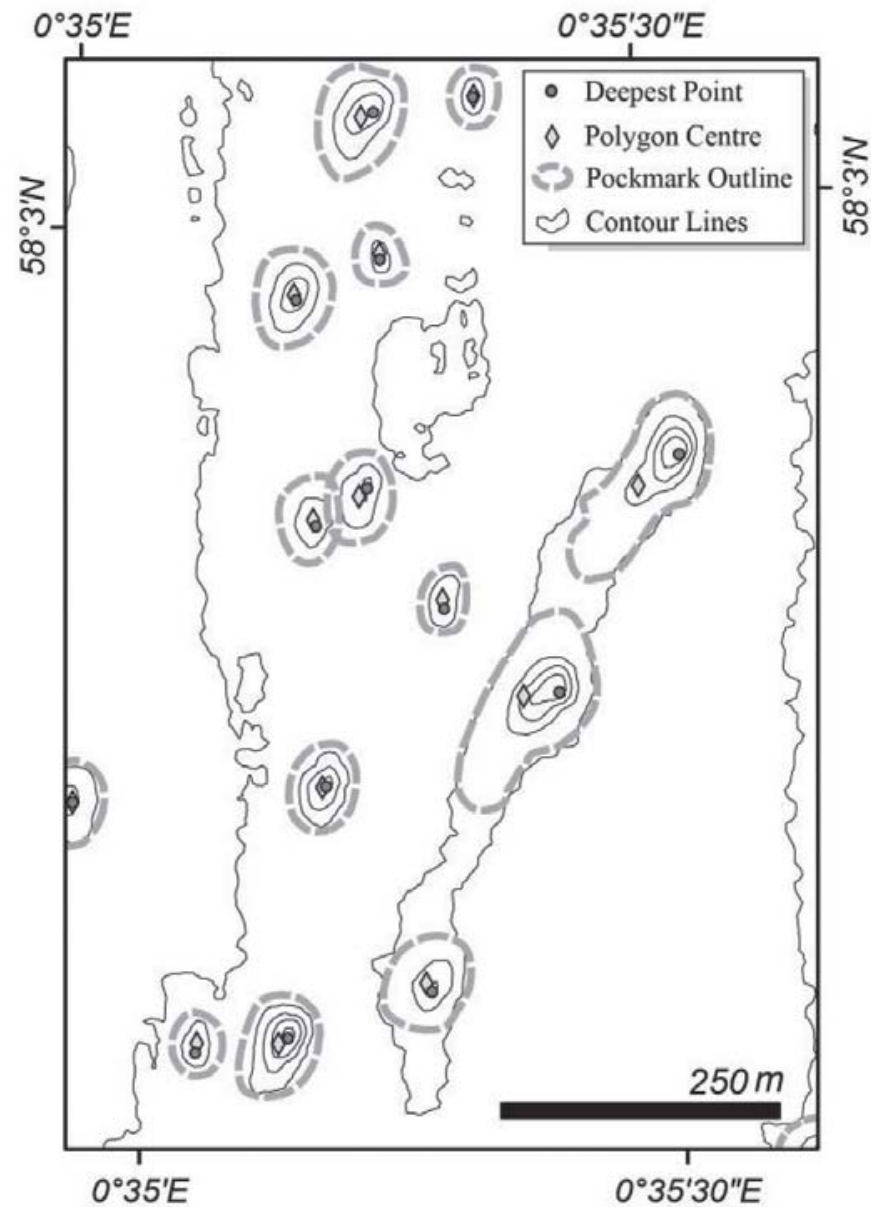

FIGURE 6 Example of the three shapefiles obtained by using the method here described. 


\section{CONSIDERATIONS}

Although the threshold values are set independently there is a certain degree of "interaction". For example, by increasing the Minimum Area threshold the minimum depth for mapped pockmarks also increases, without changes in the value for Minimum Depth threshold.

The area delineated for a $70 \mathrm{~cm}$ deep pockmark, using pockmark depth threshold of $50 \mathrm{~cm}$, will probably be smaller than the threshold set for minimal area (normally set to $100 \mathrm{~m}^{2}$ ). Therefore, most $70 \mathrm{~cm}$ deep pockmarks would not actually be mapped with this method whereas pockmarks deeper than $100 \mathrm{~cm}$ will probably all be mapped (Fig. 7). By reducing the value of the Minimum Area threshold the shallower pockmarks will be mapped, thereby indirectly reducing the minimum pockmark depth without changing the Minimum Depth threshold.

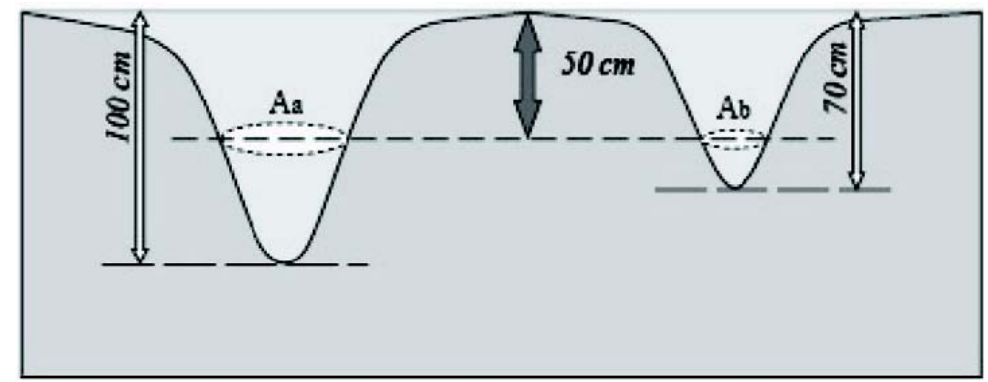

FIGURE 7 Diagram exemplifying how pockmarks slightly deeper than the Minimum Depth established threshold of for instance $50 \mathrm{~cm}$, pockmark on the right, can be excluded by presenting an area $(\mathrm{Ab})$ smaller than the Minimum Area threshold. Whereas deeper pockmarks, like the pockmark on the left, tend to present an area (Aa) higher than the value established for Minimum Area.

To validate and assess the method's accuracy the location and shape of pockmarks delineated using this method from one of the survey areas was compare to the pockmarks previously mapped manually and given in its associated site survey report. This method indentified 63 pockmarks, 6 of which had not been identified manually. The shape of the largest pockmarks matched almost exactly between both mapping exercises. The greatest differences were present on the smallest pockmarks especially those with an area smaller than a $1000 \mathrm{~m}^{2}$. Usually these pockmarks had their area underestimated when manually picked. This could reflect the tendency of the interpreter to zoom in to the DDM to map smaller pockmarks. This comparative exercise highlights the subjectivity inherent to the visual identification and manual mapping of pockmarks.

\section{RESULTS}

Using the scripts described above, 4146 pockmarks were mapped and morphometrically characterised within a tiny fraction of the time required to do such a task manually. Descriptive measurements for each of the survey areas are summarized in Table 2. With 860 pockmarks, SEA2 Box 2 was the survey site where the highest number of pockmarks was found. However, the highest pockmark density occurs within the survey site Roisin, with a pockmark density of almost 30 pockmarks per square kilometre (Table 2 and Fig. 8). The survey site with the highest average pockmark area is the SEA2 Box 3. Whereas the largest pockmarks mapped were in SEA2 Box 4, where there are five pockmarks deeper than 12 metres (one of them reaching almost 18 metres depth).

TABLE 2 Table with the results obtains for each study area, presenting the number of pockmarks delineated, pockmark density (no of pockmarks per $\mathrm{km}^{2}$ ), area of the biggest pockmark, the average pockmark area, the maximum pockmark depth and the average pockmark depth.

\begin{tabular}{|c|c|c|c|c|c|c|c|}
\hline \multicolumn{2}{|c|}{ Study Area } & $\begin{array}{c}\boldsymbol{N}^{\mathbf{o}} \text { of } \\
\text { pockmarks }\end{array}$ & $\begin{array}{c}\text { Pockmark } \\
\text { density }\end{array}$ & $\begin{array}{c}\text { Maximum } \\
\text { Pockmark } \\
\text { Area (m) }\end{array}$ & $\begin{array}{c}\text { Average } \\
\text { Pockmark } \\
\left.\text { Area (m }{ }^{2}\right)\end{array}$ & $\begin{array}{c}\text { Maximum } \\
\text { Pockmark } \\
\text { Depth (m) }\end{array}$ & $\begin{array}{c}\text { Average } \\
\text { Pockmark } \\
\text { Depth (m) }\end{array}$ \\
\hline A & Britannia A & 355 & 20.98 & 55902 & 4462 & 5.57 & 2.10 \\
\hline B & Britannia B & 382 & 17.56 & 15795 & 3623 & 4.99 & 1.74 \\
\hline C & Britannia C & 289 & 8.01 & 10204 & 2576 & 2.67 & 1.07 \\
\hline D & Britannia D & 109 & 5.11 & 14200 & 4594 & 2.78 & 1.37 \\
\hline
\end{tabular}




\begin{tabular}{|c|c|c|c|c|c|c|c|}
\hline E & Buchan & 106 & 5.01 & 21498 & 6379 & 4.40 & 2.06 \\
\hline F & Ivanhoe & 194 & 13.80 & 25184 & 4635 & 5.08 & 1.86 \\
\hline G & Petronella & 63 & 6.53 & 56749 & 12862 & 6.67 & 2.47 \\
\hline H & Rob Roy & 83 & 4.81 & 36893 & 11986 & 1.76 & 0.91 \\
\hline I & Roisin & 572 & 29.34 & 26686 & 3292 & 5.12 & 1.82 \\
\hline J & Tartan Terrace & 360 & 23.10 & 21275 & 4394 & 4.05 & 1.66 \\
\hline K & Box 01 & 76 & 10.93 & 13890 & 3889 & 4.46 & 1.86 \\
\hline L & Box 02 & 860 & 28.88 & 20927 & 3882 & 7.32 & 1.81 \\
\hline M & Box 03 & 25 & 3.99 & 69539 & 18743 & 6.75 & 3.17 \\
\hline N & Box 04 & 386 & 17.02 & 177347 & 5319 & 17.91 & 2.08 \\
\hline O & Box 06 & 84 & 12.21 & 15169 & 3025 & 6.17 & 1.58 \\
\hline P & Box 07 & 138 & 5.78 & 46052 & 11373 & 5.27 & 2.49 \\
\hline Q & Box 08 & 32 & 6.50 & 16280 & 3248 & 4.50 & 1.55 \\
\hline R & Box 09 & 32 & 2.73 & 75621 & 15571 & 5.99 & 2.94 \\
\hline
\end{tabular}

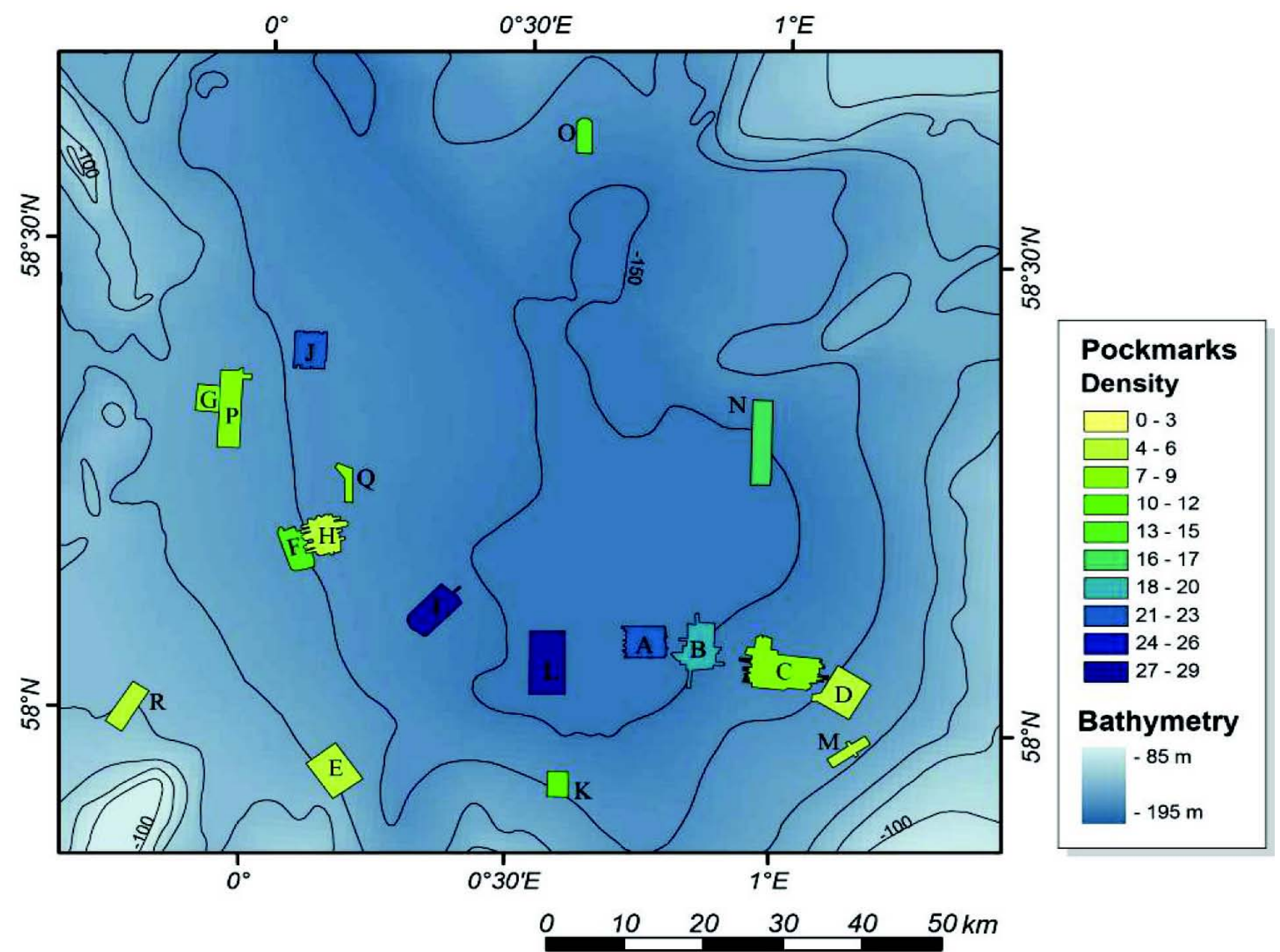

FIGURE 8

Survey sites colour coded according to the pockmark density observed. The regional bathymetry shows deeper areas (-150 m) in darker grey and shallower areas (-90 m) in light grey. 
These unusually large pockmarks, in UK licence block 15/25, have long been known as sites of active seepage (Hovland and Sommerville, 1985; Dando et al., 1991; Judd et al., 1994) and have recently been submitted as a candidate Special Area of Conservation (cSAC) under the European Habitats Directive (JNCC, 2011). They are important sites, as methane-derived authigenic carbonate is formed by the anaerobic oxidation of escaping methane, cementing the grains of sediment just below the seabed which can become exposed by subsequent pockmark activity forming a hard substrate that can attract a diverse fauna. Extensive mats of the sulphide oxidizing bacteria Beggiatoa spp. are also present. The cSAC includes the large pockmarks termed "Scanner" and "Scotia" in the south of the SEA2 Box 4 study area but not the large pockmark to the northeast termed "Challenger" (see Fig 2.39 in Judd and Hovland, 2007). They were named by Judd et al. (1994) before it was realised that both Scanner and Scotia each comprised two individual depressions as was also shown in this study. Because of the very large size of these pockmarks, in particular their depth, their morphology may partially reflect the underlying geology and changes in the physical properties of the sediments with depth (Judd et al., 1994), so their attributes may differ from those of other (inactive) pockmarks across the Witch Ground Basin.

Although this mapping method delivered robust results for most areas, it was strongly affected by the resolution of the bathymetric data. The lower resolution of the data from Rob Roy, a $10 \mathrm{~m}$ grid, prevented the correct identification and delineation of the pockmarks at seabed. That can be detected by visual assessment or by comparing the pockmark density of the adjacent survey site, Ivanhoe, which has a pockmark density of 13.8 pockmarks per $\mathrm{km}^{2}$, whereas the pockmark density within the Rob Roy area is only 4.81 (Table 2 and Fig. 8). This abrupt reduction of pockmark occurrence between these adjacent study areas does not appear to be controlled by: 1) marked changes of underlying geology, 2) distinct fluid flux or 3) variation on the nature of the seabed sediments, and can only be justified by the inability of the method to account for all the pockmarks actually present at the seabed due to the lower resolution of the Rob Roy survey data. The lower resolution also affected the morphometric characterisation of the pockmarks. This is evident by comparing the distribution trends of the pockmarks from the other survey areas and the pockmarks from the Rob Roy survey area. Figure 9 shows the relation between pockmark Area and pockmark Depth for all the pockmarks mapped. The trendline for all the survey areas follows within the area marked in grey and referred to as trendline range and show high correlation coefficients values $\left(\mathrm{R}^{2} \approx 0.85\right)$, with the exception of the trendline for the Rob Roy survey site.

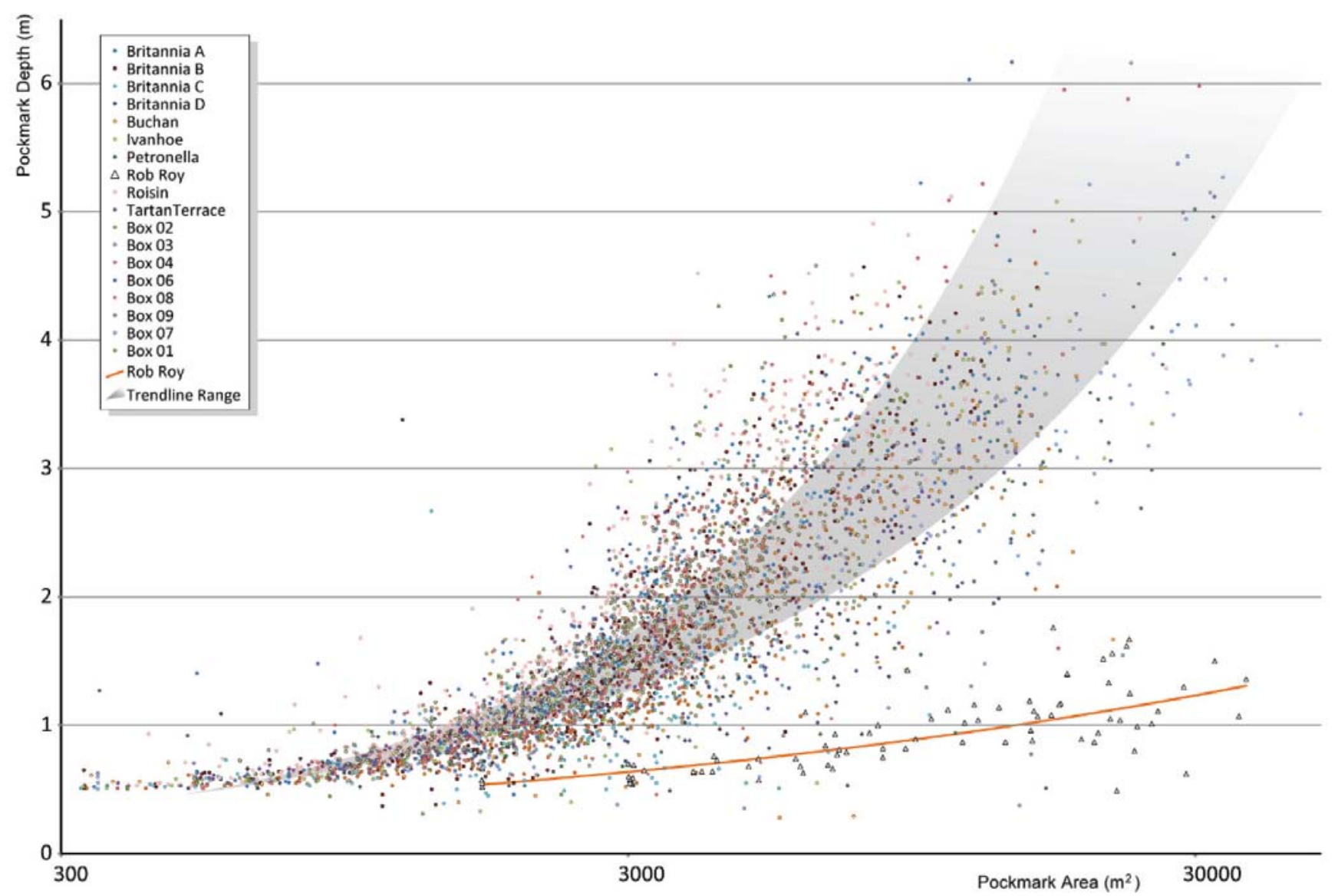

FIGURE 9 Relation between pockmark Area and Depth (d) for the 4146 pockmarks mapped. Note the logarithmic horizontal scale used for the Area axis. Orange line shows power trendline for the pockmarks mapped on the Rob Roy survey area, whereas the grey area shows the range of the power trendlines for all the other survey areas. 
Andrews et al. (2010), while describing the pockmarks present in Belfast Bay, offshore Maine, USA, indicate that larger pockmarks occur in deeper water, however from the data extracted during this work no significant correlation was found between the water depth (MinWD) and the pockmark depth $(d)$. Figure 10 shows the relation between $d$ and MinWD to all the 18 survey sites. Although there are differences related to the geological setting and range of water depths between the central North Sea and offshore Maine, the contrasting values for the strength of correlation between pockmark depth and water depth in both studies almost certainly derives from the fact that the previous authors related the pockmark depth $(d)$ with the depth of the seabed measured at the deepest point within the pockmark (which in this work is refereed as MaxWD) whereas we find that is more appropriated to use the measurements related to the rim of the pockmarks $(M i n W D)$.

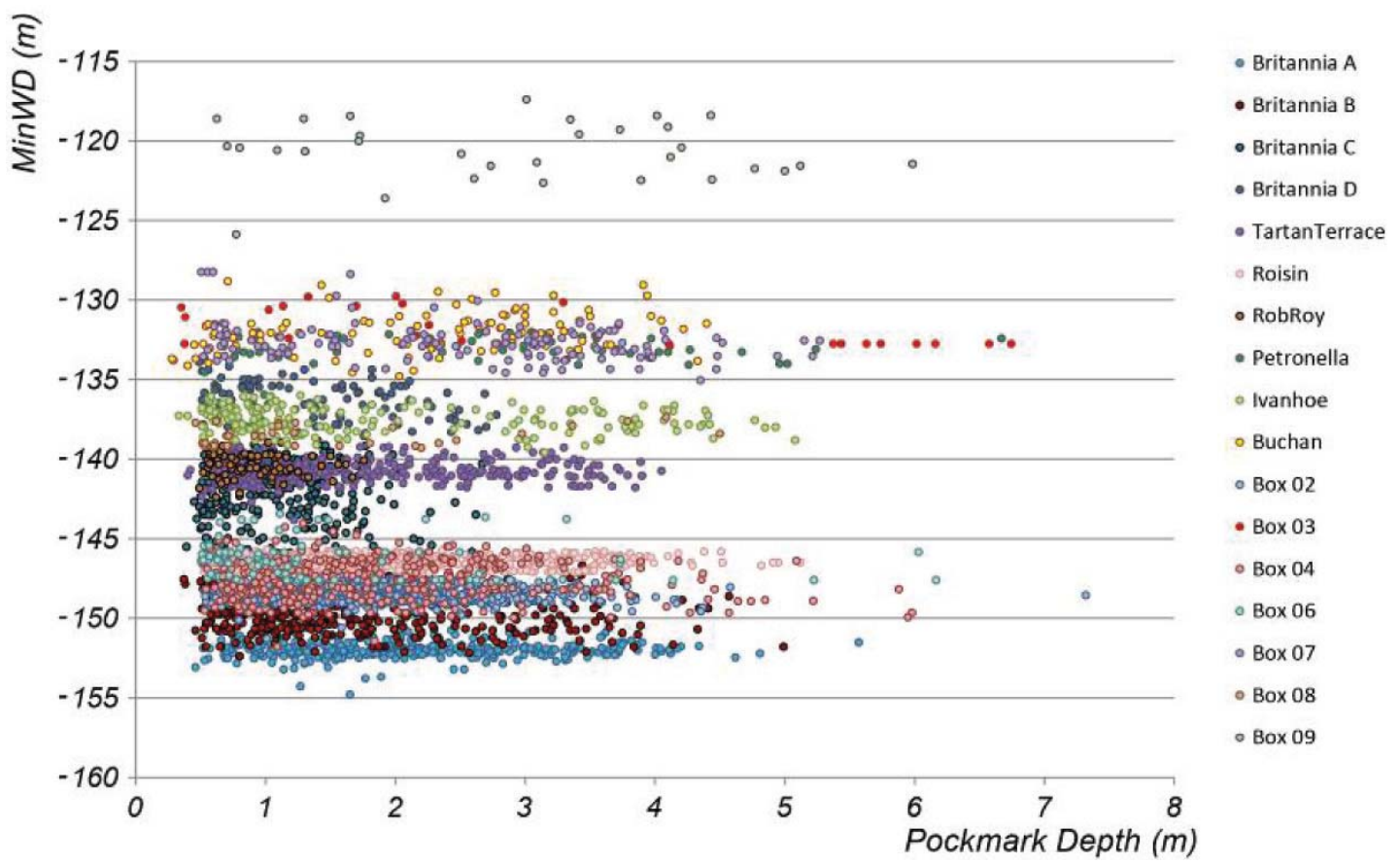

FIGURE 10 Relation between pockmark depth (d) and the minimum water depth (MinWD) for the 4146 pockmarks delineated.

\section{DISCUSSION}

The method presented in this paper creates the possibility to extract morphologic information of a vast number of pockmarks from multiple surveys in a systematic and consistent way. This is a significant improvement to the study of pockmarks, considering that it would be highly unlikely for one or multiple interpreters to maintain the same criteria throughout the laborious process of manually mapping such number of pockmarks, therefore compromising the possibility of doing any valid statistical comparison between pockmark populations.

\section{Frequency}

As noted above there are variations in the distribution of pockmarks between the different data sets examined (Table 2). This study of the central North Sea shows little variation in the depth of pockmark with water depth (Fig. 10). However, the density of pockmarks decreases from nearly 30 per $\mathrm{km}^{2}$ in the centre of the basin where water depths exceed $150 \mathrm{~m}$ and the seabed sediment is typically mud, to less than 5 per $\mathrm{km}^{2}$ on the edge of the basin where water depths are around $120 \mathrm{~m}$ and seafloor sediment is muddy sand or sandy mud (Fig. 8). The thickness of the very soft late glacial sediments within which the pockmarks are developed is greatest in the centre of the basin but thins towards the edge. This trend from the centre to the edge of the basin seems to control the number of pockmarks however they are not reflected in the average area and average depth of the pockmarks. This suggests the controls on the size of the pockmark are factors below the near seabed geology that are basin wide.

As the relationship between the area of an individual pockmark and its depth has trendlines for each data set that are similar it suggests there is similarity in the physical properties of the surficial sediments, at least the upper $5 \mathrm{~m}$ or so, across the basin. This fits with geological examination of cores across the basin (Andrews et al., 1990). 


\section{Eccentricity}

Knowing the length of the major axis and the total area $(\boldsymbol{A})$ of the polygon is sufficient to define the eccentricity (e) of each mapped pockmark. The eccentricity can be defined by the equation 1 , where $\boldsymbol{a}$ is the ellipse's major radius, $\boldsymbol{b}$ the ellipse's minor radius and $\boldsymbol{b}$ equals $\boldsymbol{A} /(\boldsymbol{\pi} . \boldsymbol{a})$.

$e=\sqrt{\frac{a^{2}-b^{2}}{a^{2}}}$

Examples of ellipses with different eccentricity values are given in Fig. 11. This parameter can be thought of as a measure of how much a given ellipse deviates from being circular and therefore it allows a comparison between pockmarks of different sizes. The eccentricity of the pockmarks mapped within the different survey sites was calculated and compared. Figure 12 shows the frequency distribution of the 860 pockmarks, mapped within SEA 2 Box 2 survey site, according to their eccentricity value. This type of distribution, with mean value near 0.70 is the most common type of distribution. However, some survey sites present different types of distribution indicating the occurrence of more or less elliptic pockmarks.

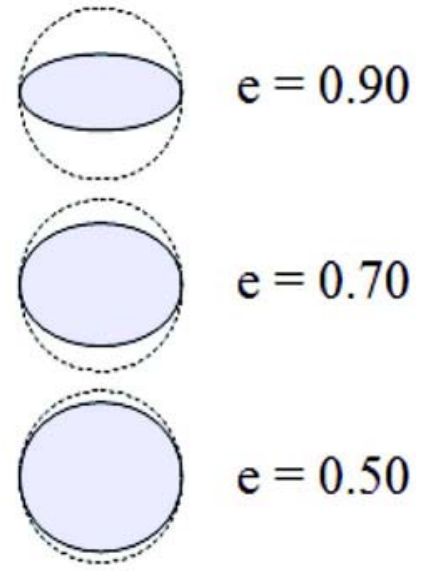

FIGURE 11 Examples of ellipses with different eccentricity values, which can vary between 0 and 1 .

Eccentricity of a pockmark will have an orientation that can be described by the azimuth of the longest axis determined by the Polygon Diameter Azimuth Tool (step 2.4, on Fig. 4). When a pockmark forms through fluid release placing fine sediment into suspension, the subsequent sedimentation of this sediment in suspension will be influenced by the prevailing currents. If there is no current the sediment can be expected to fall back to the seafloor uniformly creating a circular pockmark. However if the sediment is transported by a prevailing current an uneven spatial distribution of the material in suspension can be expected and thus the development of asymmetric pockmarks.

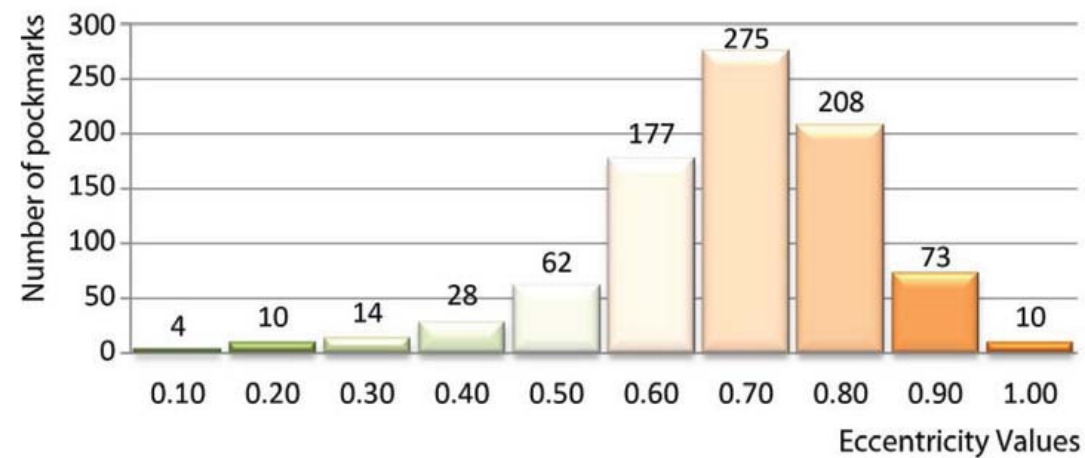

FIGURE 12 Histogram showing the survey site SEA 2 Box 02 pockmark frequency distribution according to their eccentricity.

The eccentricity orientation is clearly seen on rose diagram plots as having a strong consistency within most data sets and varies from NNE-SSW in the east of the study area to N-S or NNW-SSE in the west and north (Fig. 13). It can be assumed that this orientation reflects the orientation of the seabed currents at the time of pockmark formation. They are similar to the orientation of currents measured within $15 \mathrm{~m}$ of the seafloor recorded by current meters in the last twenty years (Fig. 14). The fact that there is a strong consistency of orientation within individual data sets implies that either all the pockmarks were formed over a very short period of time or that the modern current regime has been active for a long period of time. Whereas variation in eccentricity values, within one area, may reflect variable lengths of time of venting or changes in current strength during the individual gas seepage events.

It is thought unlikely that modern currents are reshaping the geometry of inactive pockmarks. However it is known that at least one very large pockmark shows evidence of symmetrical partial infilling after initial formation, Scanner in 15/25 (Judd et al., 1994). But as noted previously the very large pockmarks differ in many respects to the vast number of smaller pockmarks in the Witch Ground Basin and so it may not be possible to extrapolate from such evidence. Additionally, even if generalised reshaping of the pockmarks had occurred, as shown on the boomer profiles from Scanner site, the reshaping would have been by symmetrical partial infilling and thereby the reshaping would not have changed the initial eccentricity. 


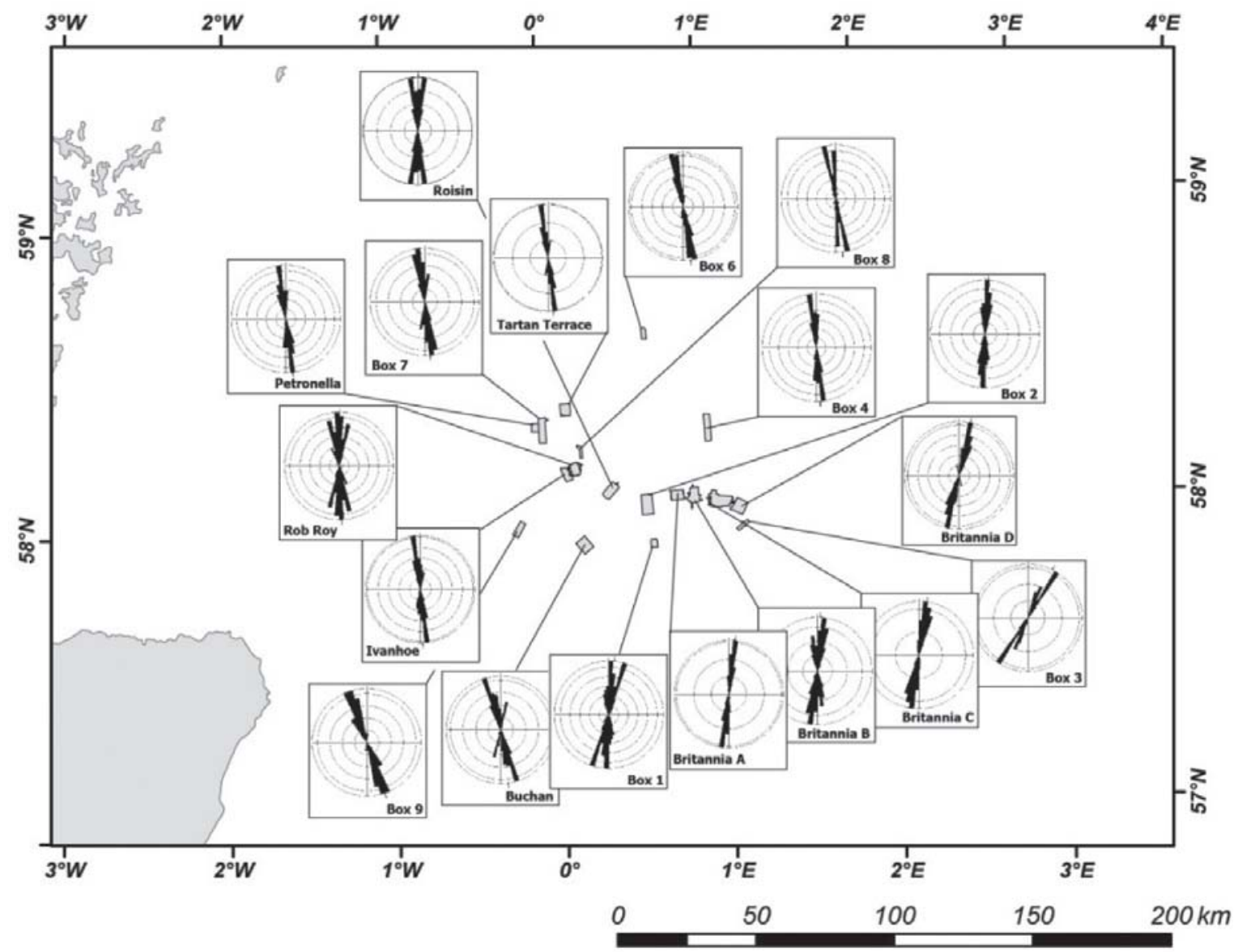

FIGURE 13 Rose diagrams showing the pockmark major axis azimuth direction for each survey area.

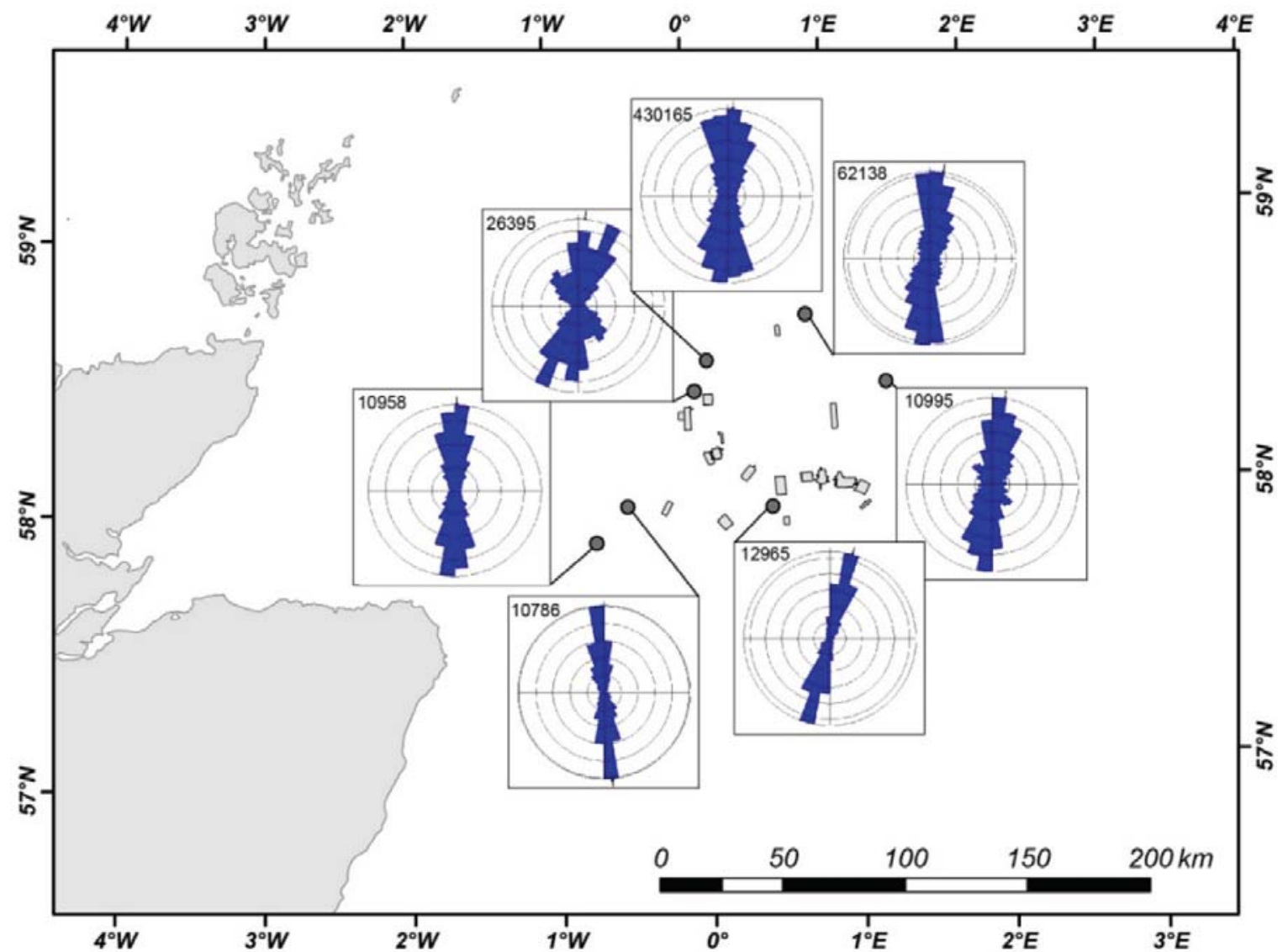

FIGURE 14 Rose diagrams showing the current directions of modern bottom waters (generally less than $15 \mathrm{~m}$ above seafloor). Data provided by the British Oceanographic Data Centre (BODC). 


\section{Spatial distribution}

An advantage of using the point shapefile that defines the likely position of the vent sites, i.e. the deepest point within the pockmark, is that the vent location can be viewed without the surrounding morphology. Figure 15 (left) shows the seabed morphology from data set L (SEA2 Box 2) with a pockmark lineation AB orientated northeast-southwest. However plotting just the vent sites (Fig. 15; right) gives a contrasting orientation for nearest neighbours such as the northwest-southeast trend CD. On a wider scale plotting vent sites within the same data set (Fig. 16) shows clusters and lineations that may reflect fracturing control on gas seepage. However there are no clear lineations suggestive of major faults, rather small rings of vents up to $0.5 \mathrm{~km}$ diameter which may be linked with polygonal faulting within the Tertiary sediments below the Quaternary but any pathway will have been greatly modified by the glacial channelling that has affected this area several times during the Quaternary (Stewart and Lonergan, 2011).
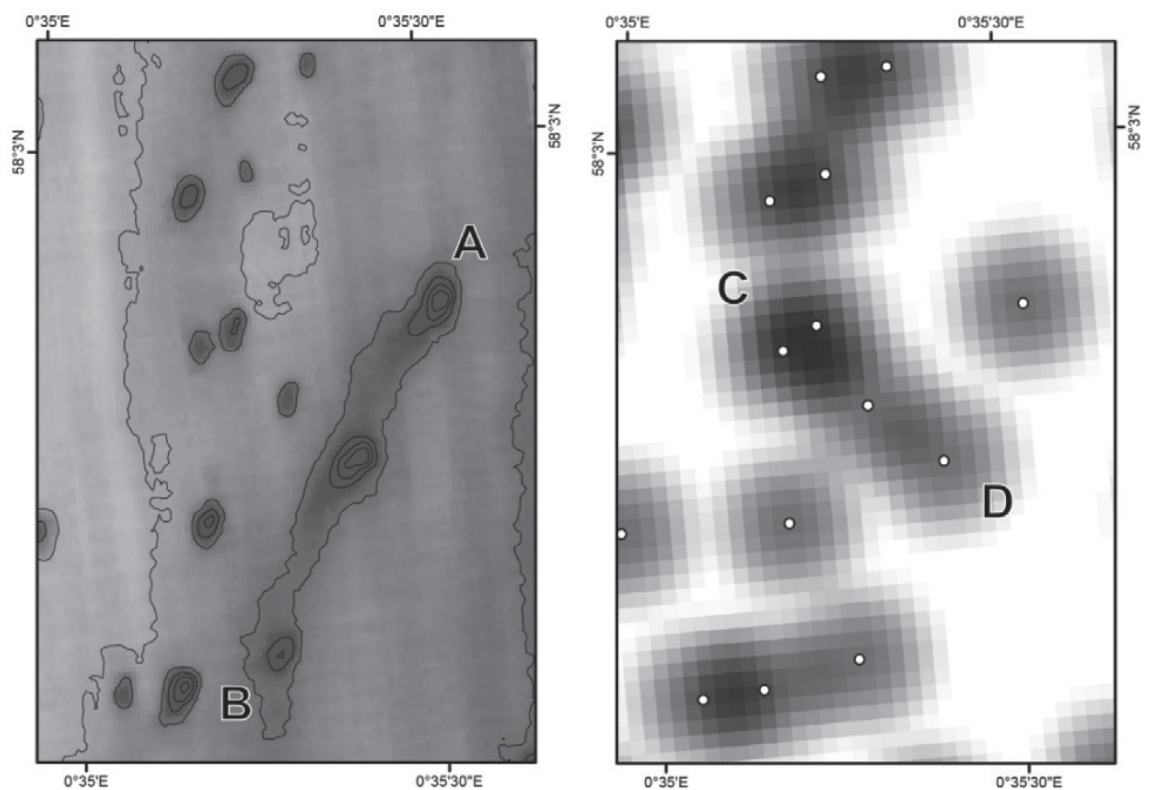

FIGURE 15 Different perceptions of pockmark spatial distribution between original DDM and pockmark density map. Left: Detail of the bathymetric map, where the geometry of the three pockmarks between the letters A and B highlight an apparent pockmark NE-SW lineation. Right: Detail of the pockmark density map highlighting the location of each pockmark vent and indicating a possible pockmark NW-SE lineation between the letters C and D.

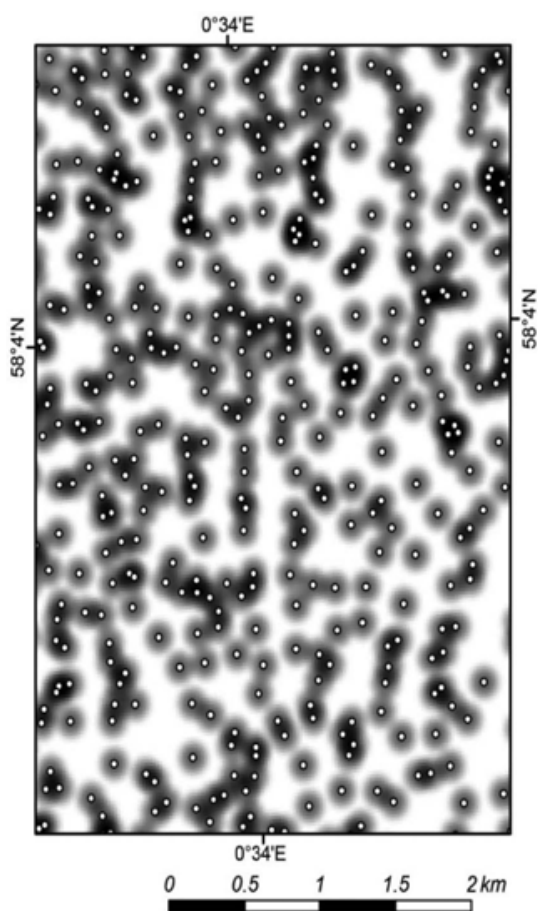

FIGURE 16 Overview of part of the SEA2 Box 2 pockmark density map and the pockmarks' deepest points, presumed venting points, where is possible to identify different pockmarks clusters and areas of the seabed without any pockmarks. 


\section{CONCLUSIONS}

Modern multibeam data sets can be used to automatically map pockmarks and to rapidly derive repeatable attributes of individual depressions. The GIS based procedure described allows data sets from different surveys to be compared. This can be used to study regional changes in size, density, spatial distribution and form. However the resolution of the xyz data set is important and $5 \mathrm{~m} \times 5 \mathrm{~m}$ is suggested as a minimum resolution.

This study of the central North Sea shows little variation in the depth of pockmark with water depth. However, the density of pockmarks decreases from nearly $30 / \mathrm{km}^{2}$ in the centre of the basin where water depths exceed $150 \mathrm{~m}$, the soft sediments of the With Ground Formation are 20-30 m thick and the surface sediment is mud, to less than $5 / \mathrm{km}^{2}$ on the edge of the basin where water depths are around $120 \mathrm{~m}$, the Witch ground Formation is less than $10 \mathrm{~m}$ thick and the seafloor sediment is muddy sand / sandy mud.

The pockmarks of the central North Sea show consistent eccentricity that coincides with the bottom water currents recorded on recent current meters, varying from NNE-SSW in the east of the study area to NNW-SSE in the west and north. This may imply that the modern current regime has been active for a long period of time.

We strongly suspect that the application of this method to different pockmark fields, over a wider range of water depths, rheology and grain size of the seabed sediments, composition and nature of the fluid escape, timing, and geological settings, combined with appropriated statistical study of data extracted, would be extremely revealing. Plus, it could also provide a useful data set for quantitative testing of any pockmark formation model.

\section{ACKNOWLEDGEMENTS}

Amerada Hess, ConocoPhillips and Talisman Energy are thanked for providing site survey reports to the national offshore database and allowing data from these reports to be used in this regional study. The DTI Strategic Environment Assessment programme is thanked for providing data from 8 surveys. The British Oceanographic Data Centre (BODC) is thanked for supplying data from recent current meters in the area. This work has been supported by the British Geological Survey ongoing regional mapping programme (MAREMAP www.maremap.ac.uk). The authors thank the reviewers, Alan Judd and Carl Fredrik Forsberg, for thoughtful comments that have improved this paper. The authors publish with the permission of the Executive Director of the British Geological Survey (NERC).

\section{REFERENCES}

Andrews B.D., Brothers L.L. and Barnhardt W.A. 2010. Automated feature extraction and spatial organization of seafloor pockmarks, Belfast Bay, Maine, USA. Geomorphology 124, 55-64.

Andrews I.J., Long D., Richards P.C., Thomson A.R., Brown S., Chesher J.A. and McCormac M. 1990. United Kingdom offshore regional report: The Geology of the Moray Firth. London: HMSO for the British Geological Survey. 93pp.

Boetius A., Ravensclag K., Shubert C. J., Rickert D., Widdel F., Glieseke A., Amann R., Jørgensen B.B., Witte U. and Pfannkuche O. 2000. A marine microbial consortium apparently mediating anaerobic methane oxidation. Nature 407, 623-626.

Brundage R. 2006. Polygon Diameter Azimuth Tool. <http://arcscripts. esri.com/details.asp?dbid=14570>.

Dando P. R., Austen M.C., Burke Jr, R.A., Kendall M.A., Kennicutt II M.C., Judd A.G., Moore D.C., O’Hara S.C.M., Schmaljohann R. and Southward A.J. 1991. Ecology of a North Sea pockmark with an active methane seep. Marine Ecology Progress Series 70, 49-63.

Hovland M. and Judd A. 1988. Seabed pockmarks and seepages: impact on geology, biology, and the marine environment. London, UK: Graham and Trotman Limited. 293p.

Hovland M. and Sommerville J.H. 1985, Characteristics of two natural gas seepages in the North Sea, Marine and Petroleum Geology 2 , 319326.

Hovland M., Gardner J.V. and Judd A.G. 2002. The significance of pockmarks to understanding fluid flow processes and geohazards. Geofluids 2, 127-136.
JNCC 2011. Scanner Pockmark

$<$ http://jncc.defra.gov.uk/protectedsites/

sacselection/sac.asp?EUcode $=$ UK0030354 $>$. Last accessed 9 February 2012.

Judd A.G. 2001. Pockmarks in the UK sector of the North Sea Technical report, Strategic Environmental Assessment of parts of the North Sea (SEA2), TR_002, Department of Trade and Industry, September 2001, 73p.

Judd A.G. and Hovland M. 2007. Seabed fluid flow: the impact on geology, biology and the marine environment. Cambridge University Press. $475 \mathrm{p}$.

Judd A.G., Long D. and Sankey M. 1994. Pockmark formation and activity, U K block 15/25, North Sea. Bulletin of the Geological Society of Denmark 41, 34-49.

King L.H. and MacLean B. 1970. Pockmarks on the Scotian Shelf. Geological Society of America Bulletin 81, 3141-3148.

Linnett L.M., Clarke S.J., Graham C. and Langhorne D.N. 1991. Remote sensing of the sea-bed using fractal techniques. Electronics and Communication Engineering Journal 3,195-203.

Long D. 1992. Devensian late-glacial gas escape in the central North Sea. Continental Shelf Research 12, 1097-1110.

McQuillin R. and Fannin N. 1979. Explaining the North Sea's lunar floor. New Scientist 1163, 90-92.

Stewart M.A. and Lonergan L. 2011. Seven glacial cycles in the middle-late Pleistocene of northwest Europe: Geomorphic evidence from buried tunnel valleys. Geology 39, 283-286. 